\title{
A Study of the Factors Influencing Non-genetic Variation in a Strain of Fusarium oxysporum
}

\author{
By M. J. CARLILE \\ Botany School, University of Cambridge
}

SUMMARY: The colour variation of a strain of Fusarium oxysporum Schlecht ex Fr. was found to depend on the production of carotenoids and naphthoquinones. The carotenoids were only produced as a result of exposure to light, whereas the production of naphthoquinones, which were $\mathrm{pH}$ indicators, was mainly regulated by the carbon/nitrogen ratio of the medium. The morphogenetic effects of radiation and of carbon/nitrogen ratio were also considered. A low carbon/nitrogen ratio favoured chlamydospore formation and aerial mycelium, whereas ultraviolet radiation, and to a lesser extent light, promoted macrospore and sclerotium production.

The identification of Fusarium spp. has presented difficulties which are only now being slowly resolved. Appel, Wollenweber and their co-workers, who have made the greatest single contribution to Fusarium taxonomy, developed a system, in particular in Die Fusarien (Wollenweber \& Reinking, 1935), which makes use of the presence or absence of microspores, chlamydospores and sclerotia, the shape and distribution of the macrospores and, to some extent, the colour and texture of the mycelium. They also introduced a cultural technique for producing the taxonomic features appropriate for identification. The small divisions which Wollenweber \& Reinking erected as species have been challenged, in recent years, on two grounds. Brown (1928) and Snyder $\&$ Hansen (1940) showed that from a mass-isolate of a species it is possible to separate, by single conidial manipulation, isolates which by the criteria of Wollenweber would be distinct species, or would even fall into distinct sections of the genus. Buxton (1954) has taken this further by showing that within the section Elegans it is possible to make heterocaryons between morphologically distinct species, i.e. as recognized by Wollenweber, and has suggested that much of the extensive variation shown by Fusarium oxysporum may be due to a redistribution of the characters in the heterocaryon in the manner demonstrated by Pontecorvo (1952) for Aspergillus nidulans (Eidam) Wirt.

The second challenge to many of the Wollenweber species has come from the demonstration of the extreme sensitivity of the fungus to environmental factors, slight changes in environment having profound effects on the observed characters. As early as 1904 it was shown by Smith \& Swingle that light affects the pigmentation of Fusarium oxysporum. Sideris (1925) examined the effect of $\mathrm{pH}$ value on pigmentation, and Brown and his co-workers in a series of papers (Brown, 1925, 1926, 1928; Brown \& Horne, 1924, 1926) studied the factors affecting the production of various taxonomic characters in $F$. fructigenum. They developed a defined medium + agar simulating the potato agar then in use, and paid particular attention to the carbon/nitrogen ratio. Their 
fungus produced only macrospores and was apparently not markedly affected by light. Ramsey \& Bailey (1930) showed that exposure to ultraviolet radiation increased macrospore production, and Harter (1939) found that cultures of Fusarium spp. grown in the light showed increased macrospore length. Snyder \& Hansen (1941) considered the effect of light on sporulation and on colour from the viewpoint of the taxonomist.

These observations have led Fusarium taxonomists to define more clearly the media and conditions under which the fusaria are grown, but difficulties still occur owing to the use of media such as potato glucose agar, which cannot by their nature be strictly defined, and by the difficulty of reproducing light of standard quality under varying laboratory conditions. With these considerations in view, an attempt has now been made to analyse the effects of various environmental factors, in particular light and nutrition, on a strain of Fusarium oxysporum under controlled conditions. The material used was an isolate derived from gladiolus corms, which proved to be particularly useful as it produced almost exclusively microspores or chlamydospores in the dark, and, under appropriate nutritional conditions, macrospores in the light. Associated with the morphological differences was a distinct colour difference.

The chemical nature of the pigments produced by fusaria is already understood in some instances. Ashley, Hobbs \& Raistrick (1937) isolated two pigments from Fusarium culmorum, rubrofusarin, which is a methylxanthone, and aurofusarin, a highly insoluble substance, the constitution of which has not been determined. The pigments of the section Martiella were investigated by Arnstein \& Cook (1947), Weiss \& Nord (1949) and Ruelius \& Gauhe (1950). The pigments successfully isolated and purified proved to be naphthoquinones. These authors, however, did not investigate the conditions which favour pigment production; this aspect has received special attention in the case of $F$. oxysporum in the following pages.

\section{METHODS}

All work was done with one single-spore isolate of Fusarium oxysporum Schlecht ex Fr. f. sp. gladioli (Massey) Snyder \& Hansen, isolated from a corm of the gladiolus variety Wedgwood, being no. 87 characterized by Buxton (1955). Stock cultures were maintained in sterile soil, and on potato glucose agar. The inoculum for use in experiments was grown on a glucose + nitrate + Difco Bacto-Agar medium to diminish the carry-over of unknown substances from the potato glucose agar, and was kept in the dark at $25^{\circ}$. A microspore suspension of standard density was used for inoculation of tubes and plates. All glassware was acid-washed. The glass constant temperature tank used for

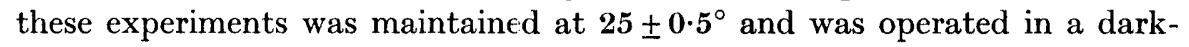
room. The lid of the tank was of plywood with holes drilled to receive testtubes, which dipped into the water.

The test-tubes used were all of the same make of Pyrex glass $(1 \cdot 5 \mathrm{~cm}$. diameter, $15 \mathrm{~cm}$. long) and contained $5 \mathrm{ml}$. of nutrient as an agar slope. The light source was a $400 \mathrm{~W}$. MA/V mercury vapour lamp supplied by Philips 
Electrical Ltd. and having the relative spectral energy distribution indicated in Table 1. The lamp was placed in a vertical position at one side of the tank at the focus of a paraboloid sheet-metal reflector. Tests with a photocell lowered into the tank and facing the lamp enabled the variations in light intensity, which were slight, to be followed, and tubes to be placed in such a manner as to receive equal illumination.

Table 1. Relative spectral energy distribution of the $M A / V$ mercury vapour lamp

$\begin{array}{lcccccccc}\text { Wavelength (A) } & \ldots & \mathbf{3 6 6 5} & 4047 & \mathbf{4 0 7 8} & \mathbf{4 3 5 6} & 4916 & \mathbf{5 4 6 1} & 5780 \\ \text { Watts } & \mathbf{5 \cdot 8} & \begin{array}{c}4.8 \\ \text { Ultra- } \\ \text { violet }\end{array} & \underbrace{4 \cdot 8}_{\text {Violet }} & 1 & \mathbf{9 \cdot 9} & \begin{array}{c}0 \cdot 3 \\ \text { Blue- } \\ \text { green }\end{array} & \underbrace{15 \cdot 3}_{\text {Yellow }} & 17\end{array}$

Tubes, wrapped in opaque black paper were placed at the back of the tank. Unwrapped tubes were placed in front in such a manner as not to interfere with each other and to receive equal illumination. Three replicates were provided for each treatment. Departures from the experimental procedure described are indicated in the text.

\section{RESULTS}

\section{General behaviour of cultures in light and darkness}

In preliminary work the fungus was grown on a wide variety of agar media under light and dark conditions. The development of the cultures is recorded in Table 2. It was concluded that light promoted the formation of orange pigments and of macrospores, whereas darkness favoured the formation of diffusible red and purple pigments and chlamydospores at a later stage in the history of the colony, provided nutritional conditions were suitable.

Table 2. Observations on the development of the fungus using a ride variety of media

\begin{tabular}{cl} 
Days & \multicolumn{1}{c}{ Light } \\
4 & Orange non-diffusible pigment \\
& Macrospores abundant \\
& No sclerotia \\
& No chlamydospores \\
$20 \quad$ Orange non-diffusible pigment \\
\\
Macrospores rare except in the form of \\
sporodochia on some media (e.g. \\
Yeastrel agar) \\
Sclerotia on some media (e.g. Czapek- \\
Dox +1.5\% glucose + agar) \\
No chlamydospores
\end{tabular}

Darkness

No pigment

Macrospores rare or absent

No sclerotia

No chlamydospores

Red or purple diffusible pigments on some media (e.g. potato glucose agar) Macrospores rare or absent

No sclerotia

Chlamydospores abundant on some media (e.g. yeast + glycerol + agar)

In the next experiment the effect of the nitrogen source upon pigmentation and morphological response was investigated. The basal medium consisted of the following constituents $(\%, \mathrm{w} / \mathrm{v})$ : Difco Bacto-Agar, 1.5; D-glucose, 2; 
$\mathrm{MgSO}_{4} .7 \mathrm{H}_{2} \mathrm{O}, 0.05 ; \mathrm{KCl}, 0.05 ; \mathrm{Na}_{2} \mathrm{HPO}_{4} .12 \mathrm{H}_{2} \mathrm{O}, 0.1$; trace elements as recommended by Beadle \& Tatum (1945); glass-distilled water. The nitrogen content of the medium was varied so as to provide the following treatments $(\%, \mathrm{w} / \mathrm{v}): \mathrm{NaNO}_{3}, 0.4(0.065 \mathrm{~N}) ; \mathrm{NaNO}_{3}, 0.04(0.007 \mathrm{~N})$; asparagin, 0.4 (0.075 $\left.\mathrm{N}\right)$; asparagin, 0.04 $(0.008 \mathrm{~N})$; Bactotryptone, $0.4(0.053 \mathrm{~N})$. Potato glucose agar was included in this treatment as a control because it is extensively used for the growth and characterization of Fusarium spp. The effect obtained with $\mathrm{NaNO}_{3}$ as the nitrogen source is indicated in Table 3. The cultures on the medium containing $0.04 \%$ asparagin, and on potato glucose agar, behaved similarly to those with $0.04 \% \mathrm{NaNO}_{3}$; whereas those with $0.4 \%$ asparagin and $0.4 \%$ Bactotryptone behaved similarly to those with $0 \cdot 4 \% \mathrm{NaNO}_{3}$. It was concluded that the carbon/nitrogen ratio was of greater importance than the nature of the nitrogen source in promoting the observed effects.

\begin{tabular}{cll}
\multicolumn{2}{c}{ Table 3. Appearance of colonies } & grown on basal medium \\
& with sodium nitrate as & the \\
$\mathrm{NaNO}_{3}(\%, \mathrm{w} / \mathrm{v})$ & \multicolumn{1}{c}{ Light } & \multicolumn{1}{c}{ Darkness } \\
$\mathbf{0} \cdot 04$ & Orange & Purple \\
& Flat & Flat \\
& Macrospores common & Macrospores absent \\
& No sclerotia & No sclerotia \\
& No chlamydospores & No chlamydospores \\
0.4 & Orange & White \\
& Aerial & Aerial \\
& Macrospores common & Macrospores absent \\
& Sclerotia in old cultures & No sclerotia \\
& No chlamydospores & Chlamydospores in old cultures
\end{tabular}

To test this an experiment was carried out keeping the nitrogen concentration constant and varying the glucose concentration. The basal medium was as used in the previous experiment with the addition of $0 \cdot 1 \%(\mathrm{w} / \mathrm{v}) \mathrm{NaNO}_{3}$. The glucose concentrations used were $0 \cdot 25,1,2$ and $5 \%$. Also employed were media with 0.25 and $5 \%$ glucose with the addition of the vitamin mixture recommended by Pontecorvo (1952). This was to test the possibility that some of the differences observed in cultures on defined media such as Czapek-Dox and on media such as potato glucose agar might be due to the presence of vitamins in the latter. The results are indicated in Table 4 . The effects of the addition of vitamins proved slight.

\section{Pigments produced only in the light}

Having determined the conditions under which pigments were produced on defined media + agar, it was necessary to learn something of their chemical nature before considering their possible significance as regards the general behaviour of the fungus. The orange pigment produced in the light by young actively growing colonies did not diffuse into the medium, did not appear to be affected by changes in the composition of the medium, and was not readily extracted by any of the commonly used solvents available. The possibility of 
the pigment being a carotenoid or mixture of carotenoids was therefore considered.

Cultures were grown on potato glucose agar in Petri dishes and after 14 days growth, during which they were exposed to daylight supplemented by continuous illumination from a mercury vapour fluorescent tube at $15 \mathrm{~cm}$. distance, the mycelium was removed from the surface of the agar. After blotting with

\begin{tabular}{|c|c|c|}
\hline$(\%, w / v)$ & Light & Darkness \\
\hline \multirow[t]{5}{*}{$0 \cdot 25$} & Pale orange & White \\
\hline & Macrospores abundant & Macrospores absent \\
\hline & Chlamydospores in old cultures & Chlamydospores in old cultures \\
\hline & No visible oil droplets & No visible oil droplets \\
\hline & Sclerotia absent & Sclerotia absent \\
\hline \multirow[t]{5}{*}{$1 \cdot 0$} & Orange & White, with a little blue \\
\hline & Macrospores common & Macrospores absent \\
\hline & No chlamydospores & Chlamydospores in old cultures \\
\hline & No visible oil droplets & No visible oil droplets \\
\hline & Sclerotia common & Sclerotia absent \\
\hline \multirow[t]{5}{*}{$\mathbf{2 \cdot 0}$} & Strong orange & Purple \\
\hline & Macrospores common & Macrospores absent \\
\hline & No chlamydospores & No chlamydospores \\
\hline & Oil droplets present & Oil droplets present \\
\hline & Sclerotia common & Sclerotia absent \\
\hline \multirow[t]{5}{*}{$5 \cdot 0$} & Strong orange & Intense purple \\
\hline & Macrospores common & Macrospores absent \\
\hline & No chlamydospores & No chlamydospores \\
\hline & Oil droplets present & Oil droplets present \\
\hline & Sclerotia absent & Sclerotia absent \\
\hline
\end{tabular}

filter-paper the mycelium was ground with anhydrous sodium sulphate. The mixture was then repeatedly extracted with peroxide-free diethyl ether until further extracts were colourless. The extracts were combined, dried with anhydrous sodium sulphate, evaporated under reduced pressure, taken up in light petroleum and chromatographed on a column of methanol-inactivated alumina.

Several fractions were found to be present and spectrophotometric readings were taken for two of the major fractions. The fractions proved to be nonsaponifiable with $60 \% \mathrm{KOH}(\mathrm{w} / \mathrm{v})$, and were epiphasic on addition of light petroleum. It was concluded from the solvent properties, spectrophotometric data and behaviour on saponification that these fractions were carotenoids, and it seems probable that the entire orange colour of the mycelium in the light is due to a mixture of carotenoids.

The cultures which received glucose in high concentrations were the most brightly coloured, in agreement with the findings of Goodwin (1952). To find how long the cultures needed to be irradiated to produce pigmentation, 3-day cultures on Czapek-Dox agar (glucose $2 \%$ ) in Petri dishes were exposed to the mercury vapour lamp at $60 \mathrm{~cm}$., the temperature being kept at 20-21 ${ }^{\circ}$ with an electric fan. Exposure for $1 \mathrm{hr}$. produced perceptible pigmentation and 
exposure for $10 \mathrm{hr}$. a strong orange colour. The greater part of the colour production took place in darkness during the $24 \mathrm{hr}$. following irradiation. Colour production was limited to the mycelium that was irradiated, laterformed mycelium being colourless. Old mycelium largely loses the power of producing carotenoids, since exposure for $14 \mathrm{hr}$. of 10-day cultures failed to cause pigmentation.

These findings are in agreement with the recent investigations of Zalokar $(1954,1955)$ on the photoactivation of carotenoid synthesis in a strain of Neurospora crassa. A photoactivation of carotenoid formation in Pyronema confluens has also been found (Carlile \& Friend, to be published), and it seems probable that this is the explanation for the orange colorations reported for many fungi when grown in the light.

\section{Pigments produced mainly in darkness}

Cultures grown in darkness on some media produced a red-purple pigmentation. The pigment developed late in the history of the colony, after mycelial growth had largely ceased. Pigment is present in the mycelium and diffuses into the medium, whether agar or liquid. In media with a high carbon/nitrogen ratio these pigments are also formed to some extent in the light, but considerably later than the carotenoids.

Extracts of pigment were obtained by disintegrating the cultures grown on potato agar in a Waring blendor with chloroform. Water and a little acetic acid were next added to the blend, which was then centrifuged. A deep red solution of pigment in chloroform was thus obtained. An alternative method of extraction was to leave chloroform on the cultures overnight. The crude pigment was very soluble in chloroform, ether, acetone, and ethanol, and fairly soluble in water. It passed from chloroform into aqueous solutions of ammonia, sodium hydroxide, or sodium carbonate, but not into sodium bicarbonate, acetic acid or hydrochloric acid. The crude pigment was red in acid solution, and purple in alkaline solution, the end-point of the colour change being about $\mathrm{pH} 8$. In aqueous solutions the pigment decolorized bromine water, and with lead acetate in methanol, an intense violet coloration was obtained. Paper chromatography indicated that the pigment was a mixture. The reactions of crude pigment suggest a mixture of substituted $5: 8$-dihydroxy-1 : 4naphthoquinones (Kuhn \& Wallenfels, 1939). Complex mixtures of such substances have been found in the closely related fusaria of the section Martiella by other workers (Arnstein \& Cook, 1947; Weiss \& Nord, 1949; Ruelius \& Gauhe, 1950). Through the courtesy of Dr E. C. Bate-Smith and Professor F.F. Nord it was possible to compare the crude pigment with samples of fusarubin, javanicin, and solanione. When the pigment was chromatographed with these substances as markers it was found that some of the fractions were closely similar in appearance and $\boldsymbol{R}_{\boldsymbol{f}}$ values to the Martiella naphthoquinones, suggesting a close similarity if not actual identity.

It was clear from earlier experiments that media containing a considerable excess of carbon over nitrogen promoted the development of purple pigment. It was not clear, however, at what level of carbon/nitrogen ratio this effect 
becomes observable. Moreover, on some media the colour developed as a bluegreen ring, reminiscent of an effect frequently observed in Fusarium caeruleum. To investigate these phenomena, Czapek-Dox medium + agar, but without sucrose, was used as a base, and glucose was added over the following ten concentrations $(\%, w / v): 1,1 \cdot 5,1 \cdot 8,1 \cdot 9,2 \cdot 0,2 \cdot 1,2 \cdot 2,2 \cdot 5,3$ and 4 . Twenty $\mathrm{ml}$. portions of each medium were added to three Petri dishes $(8.5 \mathrm{~cm}$. diameter), which were centrally inoculated with a spore suspension and incubated at $25^{\circ}$. The time of appearance of the pigment and its distance from the centre of the dish were noted (Table 5). There was a clear relationship between the glucose

Table 5. The effect of glucose concentration on the diameter of the non-pigmented area

$\begin{array}{cc}\text { Glucose } & \begin{array}{c}\text { Average } \\ \text { diameter of } \\ \text { non-pigmented } \\ \text { area (cm.) }\end{array} \\ \mathbf{1} / \mathbf{v}) & \text { No pigment } \\ 1 \cdot 5 & 6 \cdot 1 \\ 1 \cdot 8 & 5 \cdot 5 \\ 1 \cdot 9 & 5 \cdot 3 \\ 2 \cdot 0 & 5 \cdot 1 \\ 2 \cdot 1 & 4 \cdot 9 \\ 2 \cdot 2 & 4 \cdot 6 \\ 2 \cdot 5 & 4 \cdot 0 \\ 3 \cdot 0 & 3 \cdot 0 \\ 4 \cdot 0^{*} & 0.5\end{array}$

* Reading taken at 5 days; subsequent inward diffusion of pigment obliterated colourless areas. All other readings at 10 days.

content and the diameter of the non-pigmented area. With increasing glucose concentration the colour of the pigment changed from blue to red. The addition of acid or alkali to the plates showed that this was a $\mathrm{pH}$ effect, high nitrate making the medium alkaline and high glucose, acid. After the ring had appeared, inward diffusion decreased the diameter of the colourless area and sometimes obliterated it. The effects of glucose and nitrate concentrations are further indicated in Table 7.

The development of pigment as a coloured ring, the diameter of which is related to the carbon/nitrogen ratio of the medium is of interest in illustrating the extent to which diffusion of nutrients probably takes place in the culture plate system. It is suggested that with an excess of glucose the rapid exhaustion of nitrate leads to an inward diffusion of nitrate, thus altering the carbon/nitrogen ratio near the periphery to a value where pigment formation will occur. Observations were carried out in which the nutrient distribution in 8-day cultures on media with different glucose concentrations (Table 6) was examined by means of the diphenylamine test for nitrate and the Fehling's test for glucose; the initial nitrate concentration was $0.2 \%(\mathrm{w} / \mathrm{v})$. The data obtained support the diffusion hypothesis, and suggest that a changing ratio between nutrients is a possible explanation of various zoning phenomena in Petri dishes. 
The production of naphthoquinones can be regarded as a metabolic shunt operating at high glucose concentrations. Such a mechanism has been proposed as the general mode of origin of the 'Raistrick substances' formed by many fungi. On the other hand, in view of the known biological activity of many naphthoquinones it should not be assumed that they are wholly functionless.

Table 6. Glucose and nitrate distribution in 8-day cultures on media differing only in glucose concentration

\begin{tabular}{|c|c|c|c|c|c|c|c|c|}
\hline \multirow{3}{*}{$\begin{array}{c}\text { Glucose } \\
\text { concen- } \\
\text { tration } \\
(\%, w / v)\end{array}$} & \multicolumn{8}{|c|}{ Distance from centre of plate in $\mathrm{cm}$. } \\
\hline & \multicolumn{4}{|c|}{ Fehling's test } & \multicolumn{4}{|c|}{ Diphenylamine test } \\
\hline & 1 & 2 & 8 & 4 & 1 & 2 & 3 & 4 \\
\hline 1 & Blue & Blue & Blue & Blue & + & + & + & + \\
\hline $1 \cdot 5$ & Blue & Blue & Blue & Green & - & - & - & - \\
\hline 2 & Blue & Blue & Blıe & Green & - & - & - & - \\
\hline 3 & Blue & Blue & Green & Red & - & - & - & - \\
\hline 4 & Green & Yellow & Yellow & Red & - & - & - & - \\
\hline
\end{tabular}

\section{Morphological behaviour in light}

Cultures of the strain used invariably produced microspores. When exposed to summer daylight or to radiation from the mercury vapour lamp an abundance of macrospores occurred in association with the carotenoid pigmentation. Examination of the mode of origin of macrospores and microspores showed that they were essentially similar, the difference being that in macrospore formation a great elongation of the spore rudiment occurred, after which septa developed. The distinction between macrospores and microspores was not absolute, a continuous gradation of spore length and septation being present in any one culture. In view of this it was decided to regard spores longer than $21 \mu$. as macrospores. Macrospores were produced in the middle of a young colony as a pionnotal mass. As colonies grew an increase in aerial mycelium and a decrease in macrospore production occurred. In consequence, the contrast between cultures grown in light and darkness was most marked in young cultures, and for this reason it was not easy to obtain absolute figures for macrospore production/colony.

In older cultures grown on media with a low carbon/nitrogen ratio which were exposed to light for 3-4 weeks, there occurred what might be called secondary macrospore production. Discrete areas of fresh macrospore production were found scattered over the surface of the thallus. In these cases every gradation existed between a liquid drop consisting of a dense suspension of macrospores, a soft 'pustule'containing both mycelium and macrospores (a sporodochium), and a hard tangle of mycelium (a sclerotium); the precise conditions which lead to the predominance of one or the other are not clear. It is of interest that the orange pigmentation disappeared from the mycelium around a 'pustule' and became concentrated in the 'pustule'. On inspection the cytoplasm was found to have disappeared from the decolorized hyphae; a cytoplasmic flow into the developing 'pustule' is therefore suggested. 


\section{Morphological behaviour in darkness}

In cultures grown in darkness the almost total absence of macrospores was striking. When present at all they rarely exceeded $1 \%$ of the total spore production, even at the centre of the colony. On a few media, such as malt extract agar, they sometimes reached $5 \%$; the reason for such exceptions is unknown. Cultures grown in the dark have not been known to produce either sporodochia or sclerotia. Cultures on a medium with low glucose/nitrate ratio produced abundant chlamydospores at $\mathbf{2 5}^{\circ}$, and in their formation the surrounding mycelium became emptied of its cytoplasmic contents. At high glucose/nitrate ratios chlamydospores were not found but there was an accumulation of oil droplets in the mycelium of the older parts of the colony (Table 7).

Table 7. The effect of glucose and nitrate concentration on the production of pigment, oil droplets and chlamydospores in cultures grown in darkness

\begin{tabular}{|c|c|c|c|c|c|}
\hline Glucose $/ \mathrm{NaNO}_{3}$ & $\begin{array}{c}\text { Glucose } \\
(\%, w / v)\end{array}$ & $\begin{array}{c}\mathrm{NaNO}_{3} \\
(\%, \mathbf{w} / \mathbf{v})\end{array}$ & Pigment & Oil & $\begin{array}{c}\text { Chlamydo- } \\
\text { spores }\end{array}$ \\
\hline 2 & $0 \cdot 2$ & $0 \cdot 1$ & - & - & + \\
\hline 2 & $1 \cdot 0$ & 0.5 & - & - & + \\
\hline $\mathbf{5}$ & $1 \cdot 0$ & $0 \cdot 2$ & - & - & + \\
\hline $\mathbf{5}$ & $2 \cdot 0$ & $0 \cdot 4$ & - & - & + \\
\hline $7 \cdot 5$ & $1 \cdot 5$ & $0 \cdot 2$ & Ring & - & + \\
\hline 10 & $1 \cdot 0$ & $0 \cdot 1$ & Ring & - & + \\
\hline 10 & $2 \cdot 0$ & $0 \cdot 2$ & Ring & - & + \\
\hline $12 \cdot 5$ & $\mathbf{2 \cdot 5}$ & $0 \cdot 2$ & Ring & - & + \\
\hline 15 & $3 \cdot 0$ & $0 \cdot 2$ & Ring & + & Few \\
\hline 20 & $2 \cdot 0$ & $0 \cdot 1$ & + & + & - \\
\hline 20 & $4 \cdot 0$ & $0 \cdot 2$ & + & + & - \\
\hline 50 & $1 \cdot 0$ & 0.02 & + & + & - \\
\hline 50 & $5 \cdot 0$ & $0 \cdot 1$ & + & + & - \\
\hline
\end{tabular}

\section{Pigment, spore production and ultraviolet irradiation}

All young cultures exposed to light produced carotenoids and macrospores, whereas all cultures grown in the dark produced neither. An attempt was therefore made to ascertain whether a causal relationship existed between carotenoid formation and macrospore production. An $80 \mathrm{~W}$. Mazda lamp emitting $97 \%$ of its radiation in the ultraviolet region and $75 \%$ at $3650 \mathrm{~A}$. was highly effective in promoting macrospore production. Exposure for $1 \mathrm{hr}$. of a 3-day culture at a distance of $30 \mathrm{~cm}$. (temperature $22-25^{\circ}$ ) was sufficient to bring about a massive production of macrospores, about $48 \mathrm{hr}$. being required for complete development. 'This exposure did not cause carotenoid formation. The macrospore formation occurred only within the limits of growth at the time of irradiation. Exposure for $10 \mathrm{hr}$. of similar cultures to the mercury vapour lamp which emitted mainly visible light, caused intense pigment formation but no macrospore production. It is concluded that the photoactivation of carotenoid synthesis and the induction of macrospore formation are unrelated phenomena requiring different wavelengths. 
Exposure of a 10-day culture for $1 \mathrm{hr}$. to a mercury vapour lamp emitting $87 \%$ of its radiation at $2536 \mathrm{~A}$. brought about the formation of white 'pustules' consisting of macrospores after a further 9 days of incubation. The importance of ultraviolet radiation in promoting sporulation in fungi has been recognized since the work of Stevens (1928), and was established for fusaria by Ramsey \& Bailey (1930). However, in papers by Harter (1939) and Snyder \& Hansen (1941) the promotion of macrospore formation is regarded as being due to visible radiation. The notorious variability within Fusarium spp. and the differences between species makes it difficult to compare the work of various authors. However, from the work reported in the present paper, it appears that it is the ultraviolet component of radiation from either the mercury vapour lamp or from daylight that is mainly responsible for the promotion of macrospore production in $\boldsymbol{F}$. oxysporum after short exposures. It is possible that long exposures to visible radiation may have similar but weaker effects as compared with ultraviolet radiation. A further study of the effectiveness of different wavelengths on promoting sporulation is clearly desirable.

\section{DISCUSSION}

The pigments produced by the strain studied were shown to fall into two distinct groups, one group being the result of photoactivation and the other being due to high glucose concentrations in the medium. Similar work is being carried out with other species of fusaria, and it is hoped that such an approach will enable colour to be more usefully employed as a taxonomic criterion in this genus.

The demonstration that, although production of both carotenoids and macrospores is brought about by daylight, either effect can be obtained in the absence of the other, indicates that in this species there is not an obligate relationship between the two effects. Evidence has been obtained that a comparable situation exists as regards carotenoid formation and reproduction in Pyronema confluens (Carlile \& Friend, to be published). Such studies are of significance in view of suggestions that carotenoids play an important part in reproduction.

In recent years the problem of carotenoid biosynthesis has been attracting considerable attention, and attempts to identify possible precursors have so far proved unsuccessful. It would appear that organisms such as Fusarium oxysporum and Neurospora crassa in which carotenoid synthesis can be triggered by brief exposures to light could be usefully employed in investigating this problem.

Finally, the blue ring phenomenon described gives an elegant demonstration of the probable significance of radial diffusion of metabolites in the Petri dish system, a topic that has so far received little attention.

My thanks are due to Dr T. W. Goodwin (Department of Biochemistry, University of Liverpool) for advice and for facilities for the characterization of the carotenoid pigments, to Dr E. C. Bate-Smith and Dr T. Swain (Low Temperature Research 
Station, Cambridge) for assistance in the chromatographic examination of the naphthoquinones, to Dr E. W. Buxton for the isolate of Fusarium oxysporum used, to Professor F. F. Nord and Professor H. Raistrick for providing samples of fusarium pigments, and to Dr N. F. Robertson for encouragement and advice.

\section{REFERENCES}

Arnstein, H. R. V. \& Cook, A. H. (1947). Production of antibiotics by fungi. Part III. Javanicin. An antibacterial pigment from Fusarium javanicum. J. chem. Soc. p. 1021.

Ashley, J. N., HobBs, B. C. \& Raistrick, H. (1937). LV. Studies in the biochemistry of micro-organisms. LIII. The crystalline colouring matters of Fusarium culmorum (W. G. Smith) Sacc. and related forms. Biochem. J. 31, 385.

Beadle, G. W. \& Tatum, E. L. (1945). Neurospora. II. Methods of producing and detecting mutations concerned with nutritional requirements. Amer. J. Bot. $32,678$.

Brown, W. (1925). Studies in the genus Fusarium. II. An analysis of the factors which determine the growth-forms of certain strains. Ann. Bot., Lond. 39, 373.

Brown, W. (1926). Studies in the genus Fusarium. IV. On the occurrence of saltations. Ann. Bot., Lond. 40, 223.

Brown, W. (1928). Studies in the genus Fusarium. VI. General description of strains, together with a discussion of the principles at present adopted in the classification of Fusarium. Ann. Bot., Lond. 42, 285.

Brown, W. \& Horne, A. S. (1924). Studies in the genus Fusarium. I. General account. Ann. Bot., Lond. 38, 379.

Brown, W. \& Horne, A. S. (1926). Studies in the genus Fusarium III. An analysis of factors which determine certain microscopic features of Fusarium strains. Ann. Bot., Lond. 40, 203.

Buxton, E. W. (1954). Heterocaryosis and variability in Fusarium oxysporum $\mathrm{f}$. gladioli (Snyder \& Hansen). J. gen. Microbiol. 10, 71.

Buxton, E. W. (1955). The taxonomy and variation in culture of Fusarium oxysporum from Gladiolus. Trans. Brit. mycol. Soc. 38, 202.

Goodwin, T. W. (1952). The Comparative Biochemistry of the Carotenoids. London: Chapman and Hall.

Harter, L. L. (1939). Influence of light on the length of the conidia in certain species of Fusarium. Amer. J. Bot. 26, 234.

Kunn, R. \& Wallenfels, K. (1939). Über die chemische Natur des Stoffes, den die Eier des Seeigels (Arbacia pustulosa) absondern, um die Spermatozoen anzulocken. Ber. dtsch. chem. Ges. 72, 1407.

Ponteconvo, G. (1952). The genetics of Aspergillus nidulans. Advanc. Genet. 5, 141.

Ramsey, G. B. \& BaIley, A. A. (1930). Effects of ultra-violet radiation upon sporulation in Macrosporium and Fusarium. Bot. Gaz. 89, 113.

Ruelius, H. W. \& GaUhe, A. (1950). Über Fusarubin, einen Naphthochinonfarbstoff aus Fusarien. Liebigs Ann. 569, 38.

Sideris, C. P. (1925). The role of the hydrogen ion concentration on the development of pigment in fusaria. J. agric. Res. 30, 1011.

Smith, E. F. \& Swingle, D. B. (1904). The dry rot of potatoes due to Fusarium oxysporum. Bull. U.S. Bur. Pl. Ind. 55, 184.

Snyder, W. C. \& Hansen, H. N. (1940). The species concept in Fusarium. Amer. J. Bot. 27, 64 .

SNYDER, W. C. \& HANSEN, H. N. (1941). The effect of light on taxonomic characters in Fusarium. Mycologia, 33, 580.

Stevens, F. L. (1928). Effects of ultra-violet radiation on various fungi. Bot. Gaz. 86210 . 
Weiss, S. \& Nord, F. F. (1949). On the mechanism of enzyme action. XXXVII. Solanione, a pigment from Fusarium solani $\mathrm{D}_{2}$ Purple. Arch. Biochem. 22, 288.

Wollenweber, H. W. \& Reinking, O. A. (1935). Die Fusarien. Berlin: Paul Parey.

Zalokar, M. (1954). Studies on Biosynthesis of Carotenoids in Neurospora crassa. Arch. Biochem. Biophys. 50, 71.

Zalokar, M. (1955). Biosynthesis of carotenoids in Neurospora. Action spectrum of photoactivation. Arch. Biochem. Biophys. 56, 318.

(Received 29 November 1955) 